\title{
Arsenic-safe drinking water and antioxidants for the management of arsenicosis patients
}

\author{
Salamat Khandker', Ranjit Kumar Dey², A. Z. M. Maidul Islam³, Sheikh Akhtar Ahmad4 \\ and Ifthaker-Al-Mahmudi
}

${ }^{1}$ WHO Arsenic Cell, Kakrail, Dhaka, Bangladesh; ${ }^{2}$ Directorate of Health Services, Mohakhali, Dhaka, Bangladesh; ${ }^{3}$ Department of Dermatology, Bangabandhu Sheikh Mujib Medical University, Shahbag, Dhaka, Bangladesh; ${ }^{4}$ Department of Occupational Health, National Institute for Preventive and Social Medicine, Mohakhali, Dhaka, Bangladesh.

\begin{tabular}{l}
\hline Article Info \\
\hline Received: $\quad$ 10 July 2006 \\
Accepted: $\quad$ 12 August 2006 \\
Available Online: $\quad$ January 2008 \\
DOI: 10.3329/bjp.v1i2.487 \\
\\
\\
\\
\\
Cite this article: \\
Khandker S, Dey RK, Islam AZMM, \\
Ahmad SA, Ifthaker-Al-Mahmud. \\
Arsenic-safe drinking water and anti- \\
oxidants for the management of ar- \\
senicosis patients. Bangladesh J Phar- \\
macol. 2006; 1: 42-50.
\end{tabular}

\begin{abstract}
The role of arsenic-safe drinking water and antioxidants in the management of arsenicosis patients were observed. Two hundred and fifty patients of arsenicosis from an arsenic-affected area of Bangladesh were included and divided into five groups based on the source of drinking water (green- or redmarked tube well) and intake of antioxidants (vitamin A, C and E). Melanosis improved in 43 patients of the group who took arsenic-safe drinking water from green-marked tube well and antioxidants regularly. Patients of the group who took green-marked tube well water regularly but not the antioxidant showed improvement in melanosis in 22 cases. The respondents who were using red-marked tube well water and antioxidants, only two of them improved; and all other respondents either deteriorated or did not improve. The respondents who were using red-marked tube well water but not the anti -oxidant, none did show any improvement of their illness. The respondents who took antioxidants irregularly and had irregular intake of safe water, were not considered to compare the prognosis of skin lesions. Regarding keratosis, the respondents who took green-marked tube well water regularly and antioxidant regularly, 8 of them improved, 1 case didn't change; while the respondents who took green-marked tube well water regularly but not the antioxidant, 8 cases didn't improve much but majority of them remain unchanged. Among the respondents of other groups, keratosis deteriorated. This study suggests that both arsenic-safe drinking water and use of antioxidants gave good result in improvement of the arsenicosis.
\end{abstract}

\section{Introduction}

Access to safe water supply is one of the most important detriments of health and socio-economic development. In the first half of the 1970s, Bangladesh faced an infant mortality rate of around 140 per 1000 with diarrhea being a major determinant. For young children 1-4 years, diarrhea accounted for nearly half of all deaths. A solution was to provide tube wells sunk 20
-30 meter was free of harmful bacteria. At the initial stage government and other international agencies assisted the tube wells sinking. At present there are about 7-8 million tube wells to tap better quality water and $97 \%$ of rural drinking water supply is obtained from ground water sources (Ahmed and Ahmed, 2002). These tube well installation initiatives have contributed significantly to the halving of infant mortality over 36 years from 161 per 1000 in 1960 to 83 per 1000 in 1996. 
The situation became particularly complex, in 1993 when it was discovered that, substantial proportion of the tube wells were yielding water contaminated with high level of soluble arsenic compounds (WHO, 2000) to threat health and epidemiology of arsenicosis. The detection of arsenic in the ground water was first made in West Bengal in 1983 and in Bangladesh in 1987. Chowdhury et al. (2000) states that until 1995 tube well contaminated by arsenic was not wide-spread across central and southern Bangladesh. The most recent information comes from a testing project involving the collaboration of the Department of International Development (UK), the British Geological Survey, and The Government of the Peoples Republic Bangladesh. This project tested one tube well in every $36 \mathrm{Km}^{2}$ in the two thirds of the countries most affected areas and found that, $51 \%$ of the tube wells were contaminated with at least $0.01 \mathrm{mg}$ arsenic/1, 35\% with at least 0.05 $\mathrm{mg}$ arsenic/1, 25\% with at least $0.1 \mathrm{mg}$ arsenic/1, $8 \%$ with $0.3 \mathrm{mg}$ arsenic/l or more and $0.1 \%$ with $1.0 \mathrm{mg}$ arsenic/1 or more. About 24.5 million people are currently chronically exposed to high levels of arsenic (above $50 \mu \mathrm{g} / \mathrm{L}$ ) in drinking water derived from ground water supplied by millions of hand pump tube wells.

The health hazards due to this contamination have raised the serious concern to public health. The first case of arsenicosis was detected in Chomogram village of Chapai Nowabgonj District in 1994. Since then, the number of areas and number of patients were gradually increasing. To date, 38,430 individuals with visible signs of arsenic toxicity have reported from different health sources.

The arsenic poisoning in Bangladesh is chronic in nature and is caused due to contamination of ground water. The time taken to develop clinically evident effects from drinking arsenic contaminated water is generally thought to be about 10 years, but early manifestations are not uncommon (Caussy, 2005). Most of the time, the victims do not complain of symptoms until they are detected through screening survey. The present experiment to identify the arsenic cases are by external manifestations especially with the presentation on the skin called melanosis and keratosis with the history of consuming arsenic contaminated water for a prolonged period. Gangrene of peripheral organs and ulceration due to toxic effect on the small blood vessels may also be found. Cancer of skin along with cancer of some internal organs- liver, kidney, urinary bladder is not uncommon (Kaufman et al., 2001). It is also reported that even if a person having no manifestation after chronic exposure of contaminated water the chance of having cancer cannot be ruled out. The only way to save lives is to identify patients at an earlier stage before the conditions become irreversible and to provide them arsenic-safe water and supportive management.
The present knowledge about management of arsenicosis is far from satisfactory. The drugs used for chelating arsenic in acute poisoning have proved to be ineffective in chronic arsenicosis (Guha Mazumder et al., 2001). The use of arsenic-safe water may prevent progression of effects, but it is not clear whether reversal of effects is possible. Supportive therapy with nutritional improvement may play some role in diminishing symptoms and may reverse some cases of melanosis.

Use of antioxidants like vitamins A, C and E, along with discontinuation of consuming arsenic contaminated water have shown evidences of improvement and some success in arresting the progression of symptoms (Talukder, 1999). Consequently, Directorate General of Health Services (DGHS) recommended these antioxidants in use for the management of patients suffering from arsenicosis. Some experts had advocated for the use of spirulina extracts which are rich in antioxidants in treatment of arsenicosis (Sikder et al., 2000). But, conclusive scientific evidences are still not available to make recommendation in this regard. Numbers of studies are progressing on this issue, but enough evidences are yet to confirm or to reject their effectiveness (Verret et al., 2005).

Considering the above facts, the present observational study has been designed to evaluate effectiveness of the antioxidants in management of arsenicosis patients. Factors considered in this study were quality of water intake and intake of antioxidants. The purpose of the study was to see the effectiveness of antioxidant therapy in groups of arsenicosis patients taking arsenicsafe and arsenic-contaminated water, and to compare the result with groups of patients who were not receiving antioxidant therapy.

\section{Materials and Methods}

\section{Study area}

Bhanga is an Upazilla (sub-district) under Faridpur District. It is $70 \mathrm{Km}$ Southwest from the capital city, Dhaka. It is a low land area and the river Padma borders a major portion of this Upazilla. The Sitalakha and the Kumar River pass through this Upazilla too. The area covers $216.3 \mathrm{sq} \mathrm{km}$. There are 221 Villages, 12 Unions and one Paurashava in Bhanga Upazilla. The total number of populations is 230,300 (116,560 male and 113,740 female). Sanitation and water supply of this Upazilla are not satisfactory. Majority people depend on tube well water for drinking and cooking purposes. According to Bangladesh Rural Advancement Committee (BRAC) survey report (2001), above 92\% tube wells of this Upazilla are contaminated with more than permissible arsenic concentration to Bangladesh standard. Dhaka Community Hospital (DCH) 


\begin{tabular}{|c|c|c|c|}
\hline \multicolumn{4}{|c|}{ Table I } \\
\hline \multicolumn{4}{|c|}{ Source of drinking water and anti-oxidants in different groups } \\
\hline \multirow[t]{2}{*}{ Group } & \multicolumn{2}{|c|}{ Source of drinking water } & \multirow[t]{2}{*}{ Anti-oxidants } \\
\hline & Green-marked tube well & Red-marked tube well & \\
\hline I & + & - & + \\
\hline II & + & - & - \\
\hline III & - & + & + \\
\hline IV & - & + & - \\
\hline $\mathrm{V}$ & & Irregular & \\
\hline
\end{tabular}

undertook active case detection in Bhanga and so far identified 488 arsenicosis patients (DCH, 2001). List of patients was available with the health service providers and some of those listed patients were receiving treatment with antioxidants (vitamin A- 50,000 i.u; atocopherol- $200 \mathrm{mg}$; ascorbic acid- $500 \mathrm{mg}$ ) continuously for three months with two months interval for another three months. Moreover, mapping of shallow tube wells and their water quality were also recorded by local Directorate of Public Health and Engineering (DPHE) people, and the resulted marking in the tube wells made patients as well as other concerned people to know the quality of water in terms of arsenic contamination in those tube wells.

\section{Duration of study}

The study was conducted during February to September 2003. Initial two months were spent for preparation of the study, collecting socio-economic and epidemiological data and baseline clinical status of selected patients.

\section{Study population}

For the selection of study population every odd number was chosen from the list purposively. Thus a list of 244 patients was made. During our field interview we found 86 new patients. From the new patients list we selected 16 more patients randomly. In this way we prepared a list of 260 patients for interview. The patients were divided into 5 observation groups on the basis of their quality of water intake and receiving antioxidant therapy. If there were less than 50 patients for particular group new participants randomly selected to fulfill the target similarly rejected to interview patients of a particular group once the desired number was attained. Thus in each group there were 50 patients and the groups were as follows (Table I):
Group I: Drinking water from green-marked tube wells (safe water) and receiving antioxidant treatment.

Group II: Drinking water from green-marked tube wells (safe water) but were not receiving antioxidant treatment.

Group III: Drinking water from red-marked tube wells (high arsenic contaminated water) and receiving antioxidant treatment.

Group IV: Drinking water from red-marked tube wells (high arsenic contaminated water) but were not receiving antioxidant treatment.

Group V: Drinking water from both red and greenmarked tube wells (irregular quality of drinking water) and/or irregular intake of antioxidants.

\section{Development of questionnaire}

A questionnaire was developed containing general information of patients, information about source of drinking water and the duration of tube well used by the study population. The questionnaire was pre-tested and finalized after incorporation of feedback.

\section{Interviewers}

Socio-economic and water intake related data were collected by trained interviewer. Fourteen interviewers were locally recruited for the purpose, and were given one day orientation training on different techniques to fill up the questionnaire. The interviewers were divided into two groups headed by one team leader and administered a structured questionnaire to all the selected patients. The interviewers submitted filled up forms to the project manager, recruited for the purpose, who then divided the patients into different groups mentioned above based on their statements about quality of drinking water and antioxidant therapy. 


\section{Ethical issues}

The main ethical problem of this study was that a group of the study subject continued to drink arsenic contaminated tube well water. It was not possible to prevent this group to collect potable water from arsenic -contaminated water options although alternative arsenic-safe water options were installed in their neighborhoods. Even in this situation DGHS recommended antioxidants treatment for arsenicosis patients (Talukder, 1999). Local health authority used to supply the medicine free of cost. Therefore, we did not face any ethical problem for drug intervention.

\section{Data collection}

The medical officer performed clinical examinations of all those patients and recorded findings in the checklist. Thus baseline and monthly clinical examination data were recorded in the structured checklist. The medical officer was not aware which group did a particular patient belong. A group of dermatologists evaluated the skin lesions at the beginning and at the end of the study. The evaluation was done in terms of regression of melanosis and keratosis through comparing the state of lesion of previous visit. Patients' perception was also considered for evaluation of improvement. The improvement was evaluated as $+=$ improvement, $0=$ no improvement, and - = deterioration. Body mass index (BMI) was calculated as weight $(\mathrm{kg}) /$ height (meter square).

\section{Analysis of data}

Data were entered and analyzed using the SPSS software package. Only univariate analysis was done using appropriate formula. Standard deviation and mean value were also determined for each frequency distribution.

\section{Results}

Among the respondents, 59.6\% were male and $40.4 \%$ were female. The age of the respondents varied from 13 -75 years. The mean age of the respondents of different groups was 37.7, 33.3, 38.0, 36.7 and 32.1 years respectively. Maximum respondents were in the age group of 20-49 years. Mean age of the respondents of Group V and Group II were comparatively lower. Common occupations of the respondents were service $(37.7 \%)$, agriculture $(25.5 \%)$ and business $(22.7 \%)$ Others were teachers and housewives.

Most (95.6\%) of the respondents of all the groups used tube well water for drinking and cooking purposes. However, the source of domestic water differed among the respondents. Of the different sources, pond water was the major $(57.7 \%)$ source of domestic purpose. Other sources for domestic water were tube well water
$(24.2 \%)$ and river water $(15.3 \%)$. Comparatively the respondents of Group V $(49.0 \%)$ and Group I (48.0\%) used pond water less than that of other groups (Table II).

The daily drinking water requirement per person per day varied from 1-12 L. The mean water intake was 3.97 $\mathrm{L} /$ person/day. Among the Group V respondents the mean water intake was lower in comparison to the respondents of other groups which was $2.66 \mathrm{~L} /$ person/ day). The water intake per person per day was comparatively higher amongst the Group III respondents.

The age of the tube wells used by the respondents varied from 3 months to 50 years. Average age of tube well was 10.3 years. The mean years of age of the tube wells used by the Group V (7.5 years), Group I (6.1 years) and Group II (8.2 years) was comparatively lower than the tube wells used by Group III (14.0 years) and Group IV (15.9 years).

Most (97.8\%) of the respondents could not inform about the method used for measuring arsenic concentration of their tube wells. But majority of the study subjects replied correctly regarding painted color of the tube wells.

Above $96 \%$ of the respondents of each group reported that health professional advised them to abstain from drinking water of red-marked tube wells. Of them 100\% of the Group I respondents and $98 \%$ of the Group II respondents didn't use the water of red-marked tube wells for drinking and cooking purposes; while 100\% respondents of Group III and IV still using red-marked tube wells for drinking purpose (Table II).

Almost all the respondents knew about arsenicosis. Regarding a supplementary question on sources of information the participant reported that doctors and health workers made them aware about the disease.

Twenty five percent of the respondents were suffering from general weakness, cough, peptic ulcer, hypertension, diabetes mellitus etc.

The mean BMI of the patients of 5 groups was in between 19 to 21 .

Table III shows that all the patients had melanosis. Different forms of melanosis, e.g. round/hypopigmented, diffuse and both were almost homogeneously distributed in all the groups' except Group V. The Ninety four respondents $(38.8 \%)$ had keratolytic skin lesion. Of them 14 were from Group V, 9 from Group I, 31 from Group II, 13 from Group III and 27 from Group IV respectively. Eighty percent of the melanosis was defuse-melanosis, and $74 \%$ of keratosis belongs to mild stage.

The perception of all the respondents of group I felt that 
Table II

Distribution of respondents according to domestic use and drinking water sources

\begin{tabular}{|c|c|c|c|c|c|}
\hline & \multicolumn{5}{|c|}{ Source of water } \\
\hline & Shallow tube well & Deep tube well & Dug well & Pond & River \\
\hline \multicolumn{6}{|c|}{ For domestic purpose } \\
\hline Group I & 17 & 2 & 0 & 24 & 7 \\
\hline Group II & 6 & 0 & 0 & 32 & 12 \\
\hline Group III & 13 & 0 & 0 & 32 & 5 \\
\hline Group IV & 13 & 0 & 1 & 31 & 4 \\
\hline Group V & 11 & 3 & 1 & 24 & 10 \\
\hline Total & 60 & 5 & 2 & 143 & 38 \\
\hline \multicolumn{6}{|c|}{ For drinking and cooking } \\
\hline Group I & 46 & 4 & 0 & 0 & 0 \\
\hline Group II & 48 & 2 & 0 & 0 & 0 \\
\hline Group III & 50 & 0 & 0 & 0 & 0 \\
\hline Group IV & 49 & 0 & 0 & 0 & 0 \\
\hline Group V & 45 & 3 & 0 & 1 & 1 \\
\hline Total & 238 & 9 & 0 & 1 & 1 \\
\hline
\end{tabular}

they are improving from the illness by taking safe water and antioxidants regularly. The majority of respondents (38 out of 50) of group II also felt that they are improving by green arsenic -safe water only. On the other hand, a few respondents (11) of Group III felt that they are improving but all other respondents felt that they are not improving at all. It was observed that the respondents who took arsenic-safe drinking water from green-marked tube well and antioxidants regularly (Group I), melanosis improved in 43 respondents, 6 didn't improve and none was found to have deteriorated (Table IV). The respondents who took green-marked tube well water regularly but not the anti -oxidant (Group II), melanosis improved in 22 respondents, 24 did not improve and 4 deteriorated. The respondents who were using red-marked tube well water and antioxidants (Group III), only two of them improved; and all other respondents either deteriorated or did not improve. The respondents who were using red-marked tube well water but not the antioxidant (Group IV), none did show any improvement of their illness. The respondents who took antioxidants irregularly and had irregular intake of safe water, were not considered to compare the prognosis of skin lesions. 
Table III

Distribution of respondents according to skin lesions status

\begin{tabular}{|c|c|c|c|c|c|c|}
\hline \multirow[t]{2}{*}{ Group } & \multicolumn{3}{|c|}{ Melanosis } & \multicolumn{3}{|c|}{ Keratosis } \\
\hline & Round/hypopigmented & Diffuse & Both & Mild & Moderate & Severe \\
\hline I & 4 & 44 & 1 & 5 & 3 & 1 \\
\hline II & 5 & 40 & 5 & 20 & 9 & 2 \\
\hline III & 1 & 44 & 5 & 11 & 2 & 0 \\
\hline IV & 2 & 40 & 8 & 22 & 5 & 0 \\
\hline V & 1 & 31 & 18 & 12 & 2 & 0 \\
\hline Total & 13 & 199 & 37 & 70 & 21 & 3 \\
\hline
\end{tabular}

\section{Table IV}

Prognosis of respondents of different groups according to skin lesions

\begin{tabular}{|c|c|c|c|c|c|c|}
\hline \multirow[t]{2}{*}{ Group } & \multicolumn{3}{|c|}{ Melanosis } & \multicolumn{3}{|c|}{ Keratosis } \\
\hline & Improved & Not improved & Deteriorated & Improved & Not improved & Deteriorated \\
\hline I & 43 & 6 & 0 & 8 & 1 & 0 \\
\hline II & 22 & 24 & 4 & 8 & 21 & 2 \\
\hline III & 2 & 24 & 24 & 0 & 4 & 9 \\
\hline IV & 0 & 8 & 42 & 0 & 0 & 27 \\
\hline Total & 67 & 62 & 70 & 16 & 26 & 38 \\
\hline
\end{tabular}

Regarding keratosis, the respondents who took greenmarked tube well water regularly and antioxidant regularly (Group I), 8 of them improved, 1 didn't change; while the respondents who took green-marked tube well water regularly but not the antioxidant (Group II), 8 out of 31 improved much, 21 remained unchanged and 2 deteriorated. Among the respondents of other groups, keratosis deteriorated.

\section{Discussion}

The highest proportions of affected people were service holder. Usually service holders live in the Upazilla headquarter and almost $100 \%$ tube wells of sadar Upazilla are arsenic contaminated. This may be a reason why highest percent of arsenic affected people of our observation study are service holder.

As expected, more than $95 \%$ of patients were reported to drink tube well water. From 1975 to 1997, DPHE with co-operation of UNICEF was struggling to reduce mortality and morbidity of children due to waterborne diseases by ensuring bacteriological safe drinking water supply through installation of shallow tube well. At present there are about 6-8 million shallow tube well in 
the country (Ahmed and Ahmed, 2002) and 97\% of the rural drinking water supply in Bangladesh is obtained from ground water. Therefore majority of study population are using shallow tube well for drinking and cooking purposes. Massive tube well water testing started from 1997. The field staff tested tube well water for arsenic, marked red in case of high (above $50 \mu \mathrm{g} / \mathrm{L}$ ) arsenic concentration and provided health education on consequences of drinking water of red-marked tube well. As a result people are aware of the effects of using red-marked tube well. Therefore, it was logical that $96.4 \%$ of the study subject reported that they have been informed about adverse effect of drinking water from red-marked tube well. The respondents of Group III and IV are still drinking arsenic contaminated water although they are aware about the consequences. This behavioral aspect indicates the gap between knowledge, attitude, practice and scope for using arsenic-safe drinking water. Moreover, more than $32 \%$ of the patients could not correctly interpret the message of red- and green-painted tube wells.

The mean BMI of the patients of 5 groups was in between 19 to 21 that correspond to normal value of Bangladeshi people (Jahan and Hossain, 1998). Based on the finding it can be said that, on an average the study populations are maintaining a normal nutrition. Although some researcher stated that poor nutritional status may increase an individual's susceptibility to chronic arsenic toxicity, or alternatively that arsenicosis may contribute to poor nutritional status (Milton et al., 2004). Further intensive research is recommended in this field.

All the respondents had melanosis and 38\% had both keratosis and melansis. The respondents who took green-marked tube well water and antioxidant (Group I) regularly, regression of melanosis was observed, while among the respondents who took green-marked tube well water regularly but no antioxidant (Group II) did not show much regression of melanosis and majority remain unchanged. Among the respondents of other categories, deterioration of melanosis was observed. Similarly, among the respondents who took green-marked tube well water and antioxidant regularly regression of keratosis was observed after 6 months. Kosnet et al. (1990) opined on the basis of study findings that use of vitamin A analogues (retinoids) might be useful in treating precancerous arsenical dermatosis. However, recovery from chronic arsenic toxicity particularly the resulting peripheral neuropathy may take months and may not be complete. Kosnet (1999) suggested that treatment with retinoids might have promise in the treatment of chronic cutaneous arsenism.

It is observed that, the skin condition of Group III and IV deteriorated and Group II have improved but improvement was less than Group I. These finding coincides with the study report of Oshikawa et al. (2001) that drinking piped or bottled water increased the probability of regression in subjects with mild stage of arsenical lesion. Therefore, early preventive measure is recommended to control deterioration of disease.

Bangladesh Arsenic Control Society (2003) conducted a double-blind placebo-controlled trial among 319 arsenicosis patients. They treated the patients with $\beta$ carotene, ascorbic acid, a-tocopherol, selenium, zinc and folic acid in standard recommended doses for 6 consecutive months and then every alternative month for a total period of 12 months. They found significant clinical improvement of skin lesion among the treatment group. The severities of palmer and plantar keratosis were reduced after 12 months. It revealed from this study that, patients, who were taking arsenicsafe water as well as antioxidants, the improvement was more. The improvement of the disease could be observed which was evident from the skin color of the pre- and post-intervention photographs. It was observed that a combination of arsenic-safe water and antioxidant was the most effective for the management of arsenicosis patients. Ahmad et al. (1998) stated that the manifestations of chronic arsenicosis, melanosis and keratosis showed clinical improvement on treatment with vitamin $\mathrm{A}, \mathrm{E}$ and $\mathrm{C}$, withdrawal of arsenic contaminated drinking water and use of keratolytic agent where applicable. Amongst those who had used both arsenic safe drinking water and regular medications $90.5 \%$ showed improvement of melanosis, $86.4 \%$ showed improvement of keratosis but none showed deterioration. The study further stated that the observed clinical improvements almost coincided with patients' perceptions of subsidence of signs of disease. This finding is correlated to this observation study.

Comparatively only arsenic-safe water was more effective than only antioxidant treatment. Therefore, for the management of arsenicosis it could be strongly recommend for ensuring arsenic-safe water as immediate preventive measure. DGHS recommended arsenic-safe water and intervention with antioxidant e.g. vitamin A, E and C for a period of 6 months with two months interval in between. Use of antioxidant for longer than 6 months should be cautiously recommended (Talukder, 1999).

Verret et al. (2005) reported that supplementation with vitamin $\mathrm{E}$ and selenium, either alone or combination, slightly improved skin lesion status although the improvement was not statistically significant. Recently, success in the treatment of arsenicosis with indigenous medicine 'Spirulina' has been claimed. Several investigators (Sikder et al., 2000; Khan et al., 2000; Choudhury et al., 2000; Huq et al., 2000) reported that spirulina, a natural microalle, is found to be effective in 
the treatment of chronic arsenic poisoning. Misbahuddin et al. (2006) reported that alcohol extracted spirulina in combination with zinc is effective for the management of arsenicosis patients. Ahmad et al. (2006) stated that 204 newly diagnosed patients have been included in the old list of Bhanga Upazilla. They identified 18 old patients those were asymptomatic. Among them 12 were subject of this study. Ahmad et al., (2006) opined that the asymptomatic patients might have recovered due to judicious usages of treatment options.

\section{Conclusion}

The present study shows that combination of drinking arsenic-safe water and use of antioxidants give good result in improvement of the arsenicosis. It is also evident that both of the interventions have positive impact on arsenicosis patients, but further studies are required to evaluate objective prognosis as well as the individual potentiality. Considering the gap between knowledge and practice about drinking arsenic contaminated water in a considerable number of respondents, interventions are needed to motivate the people with an aim to improve the practice of patients for drinking safe water.

\section{Financial Support}

World Health Organization

\section{Ethical Issue}

This study was approved by the Ethical Committee of Bangladesh Medical Research Council, Bangladesh.

\section{Conflict of Interest}

Authors declare no conflict of interest

\section{References}

Ahmad SA, Faruquee MH, Sayed MHSU, Khan MH, Jalil MA. Ahmed R, Hadi SA. Chronic arsenicosis: Management by vitamin A, E, C regimen. JOPSOM. 1998; 17: 19-26.

Ahmad SA, Rahman MS, Ullah MHSS, Khan MH, Faruquee $\mathrm{MH}$, Karim N. Re-screening of arsenicosis patients in UNF funded 3 Upazillas. WHO-EH Unit; 2006, p 27.

Ahmed MF, Ahmed CM (eds). Arsenic mitigation in Bangladesh. Ministry of Local Government, Dhaka, 2002, pp 20-25.

Bangladesh Arsenic Control Society. Double-blind, randomized, placebo-controlled trial of antioxidant vitamins and minerals in the treatment of chronic arsenic poisoning in Bangladesh. BACS, Dhaka, 2003, pp 1-103.

Bangladesh Rural Advancement Committee (BRAC). Tube well screening report in Bhanga Upazilla, BRAC, Dhaka, 2001, pp 1-22.

Caldwell BK, Caldwell JC, Mitra SN, Smith W. Searching for an optimal solution to the Bangladesh water crisis. Soc Sci Med. 2003; 56: 2089-96.

Caussy D. Field guide for arsenicosis case detection, disease surveillance and patient management. WHO-SEARO, New Delhi, 2005, pp 1-24.

Choudhury SAR, Khan AK, Misbahuddin M, Islam AZMM, Sahjahan M. Role of spirulina in the treatment of chronic arsenic poisoning. Bangladesh Armed Forces Med J. 2000; 27: $181-85$.

Chowdhury UK et al. Ground water arsenic contamination in Bangladesh and West Bengal, India. Environ Health Perspect. 2000; 108: 393-97.

Debra SM, Stephen EW, David MC. n-Acetylcysteine in the treatment of human arsenic poisoning. J Am Board Fam Pract. 1990; 3: 293-96.

Dhaka Community Hospital (DCH). Arsenicosis patient list of Bhanga Upazilla. Arsenic patient identification and management in 7 Upazilla, DCH, Dhaka, 2001, pp 1-11.

Guha Mazumder DN, De BK, Santra A, Ghosh N, Das S, Lahiri $\mathrm{S}$, Das T. Randomized placebo-controlled trial of 2,3dimercapto-1-propanesulfonate (DMPS) in therapy of chronic arsenicosis due to drinking arsenic contaminated water. Clin Toxicol. 2001; 39: 665-74.

Huq MA, Misbahuddin M, Choudhury SAR. Spirulina in the treatment of chronic arsenic poisoning. Bangladesh J Physiol Pharmacol. 2000; 16: 15-16.

Jahan K, Hossain M. Nature and extent of malnutrition in Bangladesh. Bangladesh National Nutrition Survey 1995-96. University of Dhaka, Dhaka, 1998, p 143.

Kaufmann RB, Sorensen BH, Rahman M, Streatfield K, Persson LA. Addressing the public health crisis caused by arsenic contamination of drinking water in Bangladesh. World Bank, Dhaka, 2001, pp 1-30.

Khan MAK, Choudhury SAR, Misbahuddin M, Islam AZMM, Shahjahan M. Effects of spirulina in the treatment of chronic arsenic poisoning in Bangladesh. Bangladesh J Med Sci. 2001; 7: 223-31.

Kosnet JM, Kreiss K. Agency for toxic substances and disease registry (ATSDR). Case studies in environmental medicine. Arsenic toxicity, 1990, p 18.

Kosnet JM. Clinical approaches to the treatment of chronic arsenic intoxication: From chelation to chemoprevention. Arsenic exposure and health effects, Elsevier Science, 1999, pp 349-54.

Milton AH, Hassan S, Shahidullah SM, Sharmin S, Jakariya M, Rahman M, Keith D, Smith W. Association between nutritional and arsenicosis due to chronic arsenic exposure 
in Bangladesh. Int J Environ Health Res. 2004; 14: 99-108.

Misbahuddin M, Islam AZMM, Khandker S, Ifthaker-AlMahmud, Islam N, Anjumanara. Efficacy of spirulina extract plus zinc in patients of chronic arsenic poisoning: A randomized placebo-controlled study. Clin Toxicol. 2006; 44: $135-41$.

Oshikawa S, Geater A, Chongsuvivatwong V, Piampongsan T, Chakraborti D, Samanta G, Mandal B, Hotta N, Kojo Y, Hironaka H. Long-term changes in severity of arsenical skin lesions following intervention to reduce arsenic exposure. Environ Sci. 2001; 8: 435-48.

Sikder MS, Islam AZMM, Khan MAK, Huq MA, Choudhury
SAR, Misbahuddin M. Effect of spirulina in the treatment of chronic arsenicosis. Bangladesh J Dermatol Venereal Leprol. 2000; 17: 9-13.

Talukder KR. The diagnosis and management of arsenicosis cases, Learning module, environmental and occupational health (including arsenic) unit, Directorate General of Health Services, Dhaka, 1999.

Verret WJ, Chen Y, Ahmed A, Islam T, Parvez F, Kibriya MG, Graziano JH, Ahsan H. A randomized, double-blind placebo -controlled trial evaluation the effects of vitamin $\mathrm{E}$ and selenium on arsenic-induced skin lesions in Bangladesh. J Occup Environ Med. 2005; 47: 1026-35. 